\title{
Effect of Urinary Retention on the Satisfaction and Complication Rate in Benign Prostatic Hyperplasia Patients Undergoing Prostatectomy
}

\author{
Mai A. Banakhar, MBChB, SsC-Urol \\ Assistant Professor, Consultant Urology, Department of Urology, Faculty of Medicine \\ King Abdulaziz University, Jeddah, Saudi Arabia
}

\section{Correspondence}

Dr. Mai A. Banakhar

P.O. Box 80216, Jeddah 21589

e.M: mbanakher@kau.edu.sa

Submission: 15 Apr. 2016

Accepted: $\quad 30$ May 2016

\section{Citation}

Banakhar MA. Effect of urinary retention on the satisfaction and complication rate in benign prostatic hyperplasia patients undergoing prostatectomy. JKAU Med Sci 2016; 23 (3): 2329. DOI: 10.4197/Med. 23.3.3

\begin{abstract}
A cohort study from January 2000 till January 2005 included all patients who underwent prostatic surgery with histopathology report of benign prostatic hyperplasia. Patients were divided into elective or retention group. Data of patient demographics, satisfaction and postoperative complications were collected. Total of 119 patients, retention ( $n=30)$, elective group $(n=89)$. Retention rate was $25 \%$. There was no effect of retention on postoperative complication (elective $=44 \%$, retention $=41 \%$ ) $p$ value $=0.826$, odds ratio 0.878 , $\mathrm{Cl}(0.363-2.124)$ nor any effect on patients' satisfaction (elective $=$ $54 \%$, retention $=59 \%) \mathrm{p}$ value $=0.661$, odds ration $=1.256, \mathrm{Cl}(0.520$ - 3.034). Patients' age and prostate size did not show any effect on postoperative outcome. While presence of inflammatory cells in benign prostatic hyperplasia (BPH) histopathology showed positive effect on satisfaction (BPH alone $=47 \%, \mathrm{BPH}+$ inflammation $=71 \%$ ) $p$ value $=0.037$, and a protective effect on postoperative complications $(\mathrm{BPH}$ alone $=45 \%,+\mathrm{BPH}$ with inflammation $=18 \%) \mathrm{p}$ value $=0.167$. Conclusion: Retention rate is comparable to the international reports. The presence of inflammatory cells in the benign prostatic hyperplasia histopathology showed a positive effect on postoperative satisfaction.
\end{abstract}

\section{Keywords}

Benign prostatic hyperplasia; Prostatectomy; Satisfaction;

Postoperative outcome

\section{Introduction}

cute urinary retention (AUR) presents in 0.4 $25 \%$ of urological practice and as an indication for transurethral resection prostate (TURP) in 25 30\%. In Proscar Long-Term Efficacy and Safety Study (PLESS) pharmaceutical trial acute urinary retention occurred in $3 \%$ of treatment arm, and $7 \%$ of placebo arm; while in Prostate World Study Group (PROWESS) trial acute urinary retention represents $1 \%$ in treatment arms and $2.5 \%$ in placebo arm. In Saudi Arabia, Mosli et al. reported that till year 2000, the rate of benign prostatic hyperplasia (BPH) patients presenting with urine retention reached $57 \%$ in some Saudi hospitals compared to the international reports of $30 \%{ }^{[1]}$. With the doubled incidence of acute urinary retention in 
our country we questioned its effect on prostatectomy postoperative outcome. We constructed this study looking for the effect of urinary retention on satisfaction and complication rate in patients who underwent prostatectomy.

\section{Material and Methodology}

A cohort study, from January 2000 till January 2005 included all BPH patients who underwent prostatic surgery (TURP), bladder neck incision (BNI), and open prostatectomy. Their histopathology was reviewed. We included patients whose histopathology report was benign prostatic hyperplasia with or without inflammation while the malignant histopathology (prostate cancer, atypical small acinar proliferation (ASAP) and prostate intracytoplasmic neoplasia (PIN)) were excluded. Patients were divided into elective group (who underwent prostatic operation and admitted on elective basis) or retention group (who underwent prostatic operation with a history of recurrent or refractory retention). Patients' demographics, prostate size, patient age and histopathology, satisfaction and postoperative complications were collected. Patients have given their informed consent and the study protocol has been approved by the institute's ethical committee.

\section{Outcome Measurement}

The study's primary outcome is postoperative satisfaction and complication rate. Patient satisfaction was assessed using a direct questionnaire (Appendix 1), which was submitted to all postoperative patients (after

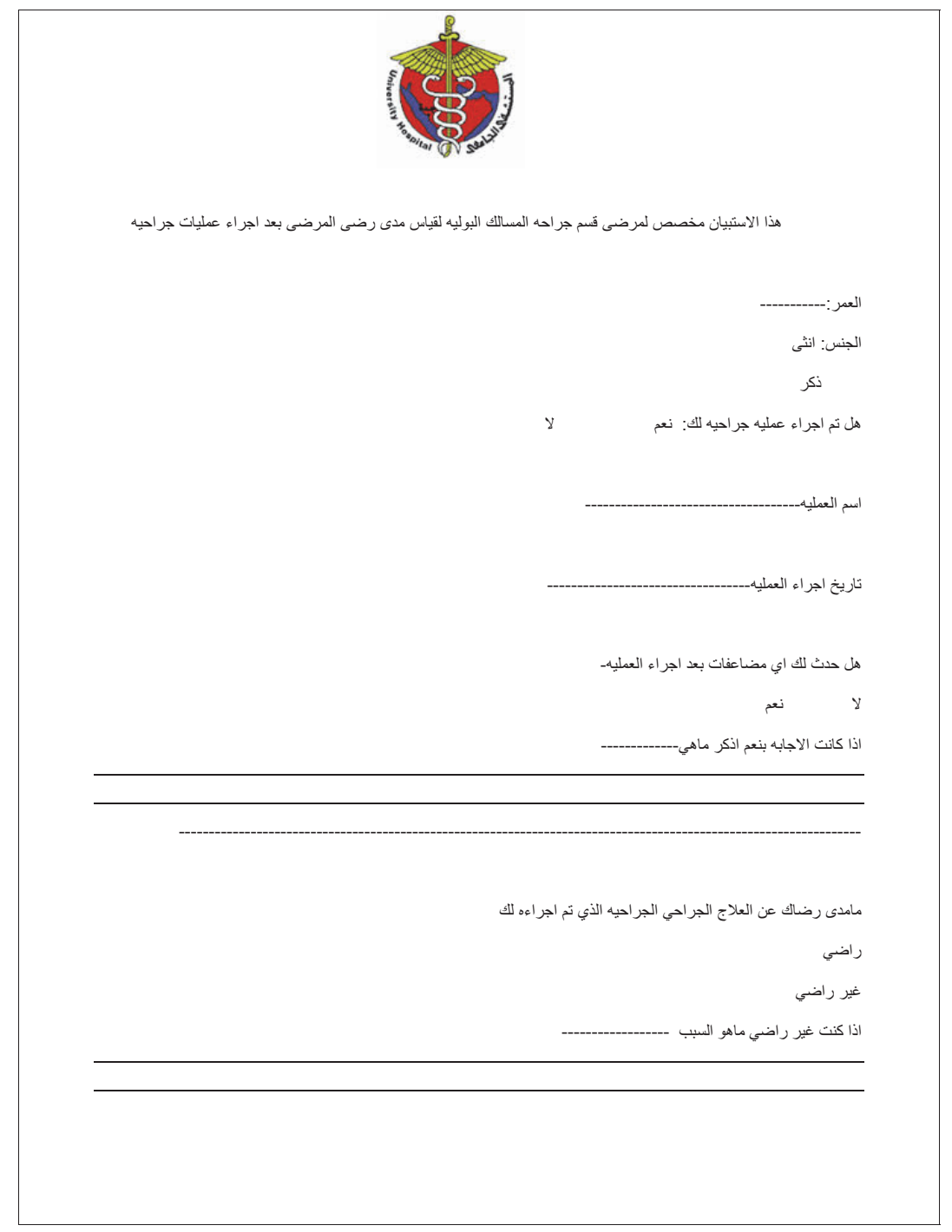

Appendix 1. Patient satisfaction questionnaire used in our study. 
6 - 12 months) in the waiting area during their clinic visit. The questionnaire asks for patients' demographics and if they are satisfied or not with the operation done.

Complications were retrieved from patients' medical files for any documentation of at least one of the following complications occurring within 12 months postoperatively in the absence of coassociation with other different causes. Complications sought included: Bladder neck obstruction, failure to void, urge urinary incontinence, retrograde ejaculation, urinary tract infection, urethral stricture, and stress urine incontinence.

The study secondary outcomes include patients age (which were recorded at the time of operation), prostate size (which was assessed using transabdominal ultrasound done preoperatively), and histopathology of BPH with inflammation confirmed by the presence of inflammatory cells in prostate resected tissue during the operation.

\section{Surgical Procedure}

All patients underwent prostate operations either TURP, BNI or transvesical prostatectomy in a standard step by different surgeons. All procedures were done under general or spinal anesthesia, with prophylactic antibiotic and all patients were continued on ciprofloxacin $500 \mathrm{mg}$ orally twice a day for 14 days.

\section{Exclusion Criteria}

All patients diagnosed with prostate cancer, or if their TURP resected tissue histopathology showed any prostate cancer, ASAP and PIN were excluded.

\section{Statistical Analysis}

Data were collected using Microsoft Excel 2003 (Microsoft Corp., Redmond, WA USA). Statistical analysis was performed using SPSS for Windows, Version 15.0 (SPSS Inc., Chicago, IL USA) cross-tab, chi-square test with risk estimate were used for data analysis. All values are considered statistically significant at $P$ values $\leq 0.05$.

\section{Results}

The total study sample of 119 were further divided into two study groups: the retention group, including patients who underwent prostatic operation with a history of recurrent or refractory retention $(n=30)$; and elective group, who underwent prostatic operation and admitted on elective basis $(n=89)$. Both the retention and elective groups had a comparable means $65 \mathrm{y}, 63 \mathrm{y}$, respectively. Procedures performed for the retention group included 93\% TURP, 7\% open prostatectomy, while in the elective group $84 \%$ had TURP, $1 \%$ had open prostatectomy and $15 \%$ BNI.

Histopathology review for the retention group showed $63 \%$ with pure $\mathrm{BPH}$ histopathology while $37 \%$ included inflammatory response in the $\mathrm{BPH}$ histopathology. The elective group had $84 \% \mathrm{BPH}$ and $7 \% \mathrm{BPH}$ with inflammation.

Retention rate in our study was $25 \%$. There was no effect of retention on patients' satisfaction rate (elective group $=54 \%$; retention group $=59 \%) p$ value $=0.661$, odds ratio $=1.256$, confidence interval $(\mathrm{Cl})(0.520$ 3.034) nor any effect on postoperative complication rate (elective group $=44 \%$; retention group $=41 \%$ ) $\mathrm{p}$ value $=0.826$, odds ratio $0.878, \mathrm{Cl}(0.363-2.124)$, urinary tract infection (UTI) $5 \%$ and $7 \%$, bladder neck obstruction (BNO) $5 \%$ and 0 - retrograde ejaculation (RGE) $4 \%$ and 0 - urethral stricture $17 \%$ and $7 \%$, urge incontinence $9 \%$ and $4 \%$, stress incontinence $0-4 \%$ failure to void $2 \%$ and $4 \%$ in elective and retention group, respectively) (Table 1).

Secondary analysis of our study group identified other factors that can affect the postoperative outcome. Patients age and prostate size did not show any effect with $p$-value $=0.471 \mathrm{Cl}(1.56-6.92)$, and $0.441 \mathrm{Cl}(8.32$ $-2.69)$, respectively.

While the presence of inflammatory cells in the BPH histopathology showed positive effect on satisfaction $(\mathrm{BPH}$ alone $=47 \%, \mathrm{BPH}+$ inflammation $=$ $71 \%) p$-value $=0.037$, and a protective calculated effect on postoperative complications (BPH alone $=45 \%$, $\mathrm{BPH}+$ inflammation $=18 \%$ ), the $\mathrm{p}$ value $=0.167$ is not significant because of the absence of histopathology specimen in BNI procedures (Figs. 1, 2, and 3).

\section{Discussion}

Benign prostatic hyperplasia (BPH) is the expected disease in most aging men with symptoms reported in $25 \%$ of men over 40 years and more than $30 \%$ of men over 65 years, affecting their quality of life ${ }^{[1-8]}$. Benign prostatic hyperplasia can lead to complications such as acute urinary retention (AUR) and BPH- related surgeries $^{[8]}$.

In fact, acute urinary retention is an indication for operation in $20-30 \%$ of BPH patients. In Saudi Arabia 
Effect of Urinary Retention on the Satisfaction and Complication Rate in Benign Prostatic Hyperplasia Patient...

M.A. Banakhar

Table 1. Patients' demographics and primary analysis results comparing retention and elective groups.

\begin{tabular}{|l|c|c|}
\hline \multicolumn{1}{|c|}{ Total Number } & Retention Group & Elective Group \\
\hline 119 & 30 & 89 \\
\hline Mean Age & 65 years & 63 years \\
\hline Operative Procedures & & \\
-TURP & $93 \%$ & $84 \%$ \\
-Open Prostatectomy & $7 \%$ & $1 \%$ \\
-BNI & 0 & $15 \%$ \\
\hline Histopathology & & \\
-BPH & $63 \%$ & $89 \%$ \\
-BPH + Inflammation & $37 \%$ & $7 \%$ \\
\hline Satisfaction Rate & $59 \%$ & $54 \% \quad \mathrm{p}=0.661,0 \mathrm{dds} 1.256$ \\
\hline Complication Rate & $41 \%$ & $44 \% \quad \mathrm{p}=0.826,0 \mathrm{dds} 0.878$ \\
-Urinary Tract Infection & 7 & 5 \\
-Bladder Neck Obstruction & 0 & 5 \\
-Retrograde Ejaculation & 0 & 4 \\
-Urethral Stricture & 7 & 17 \\
-Urge Incontinence & 4 & 9 \\
-Stress Incontinence & 4 & 0 \\
-Failure to Void & 4 & 2 \\
\hline TURP: Transurethral resection prostate; BPH: Benign prostatic hyperplasia; BNI: Bladder neck incision.
\end{tabular}

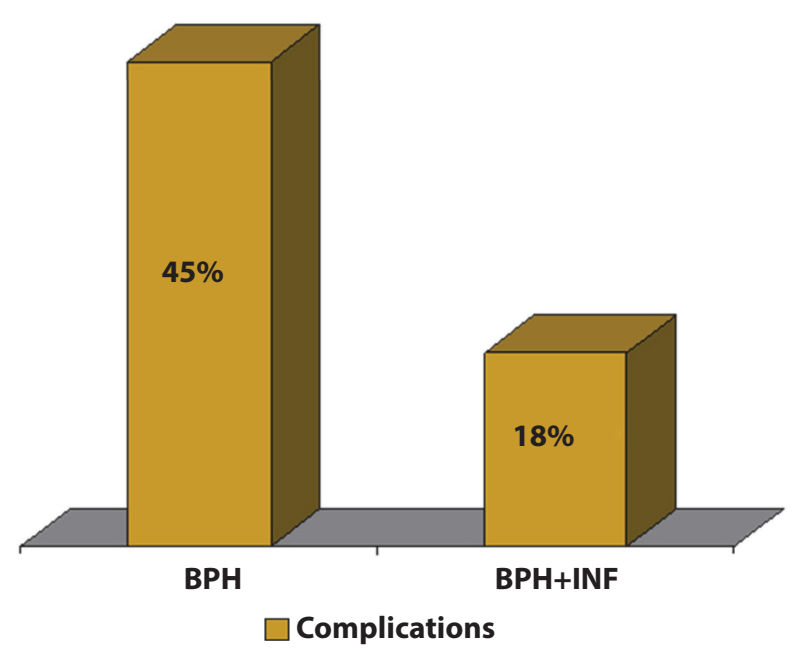

Figure 1. Postoperative complication rates difference when patients were divided according to their histopathology and the presence or absence of inflammatory cells. (BPH: Benign prostatic hyperplasia; BPH+INF: Benign prostatic hyperplasia + inflammation).

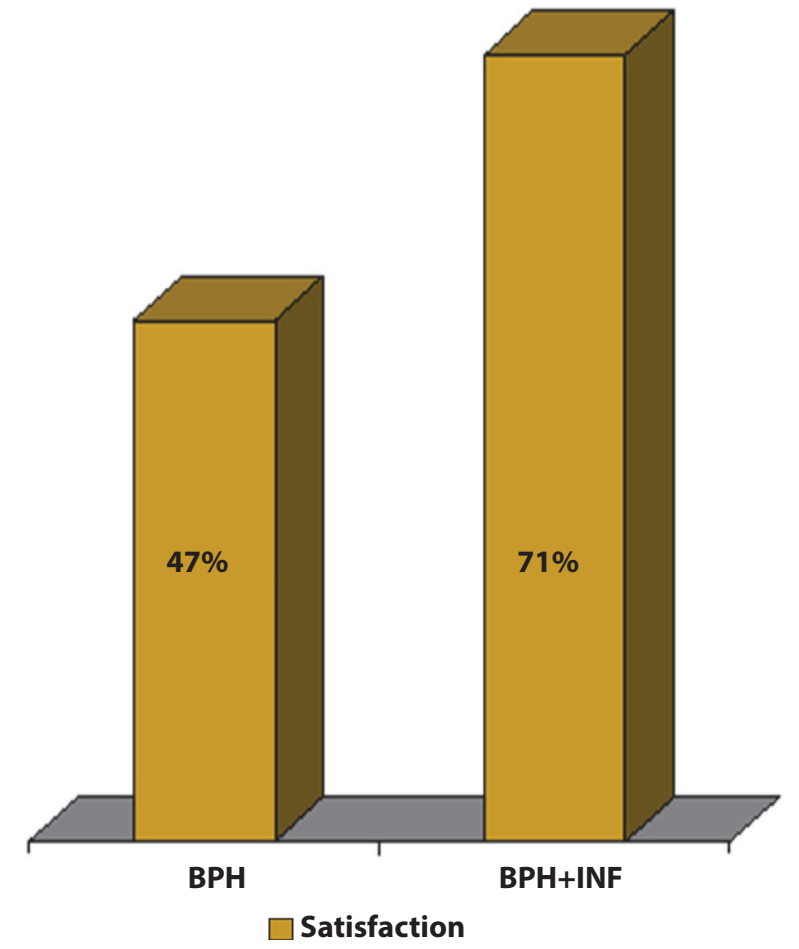

Figure 2. Post-operative satisfaction rate difference when patients were divided according to their histopathology. (BPH: Benign prostatic hyperplasia; BPH+INF: Benign prostatic hyperplasia + inflammation). 


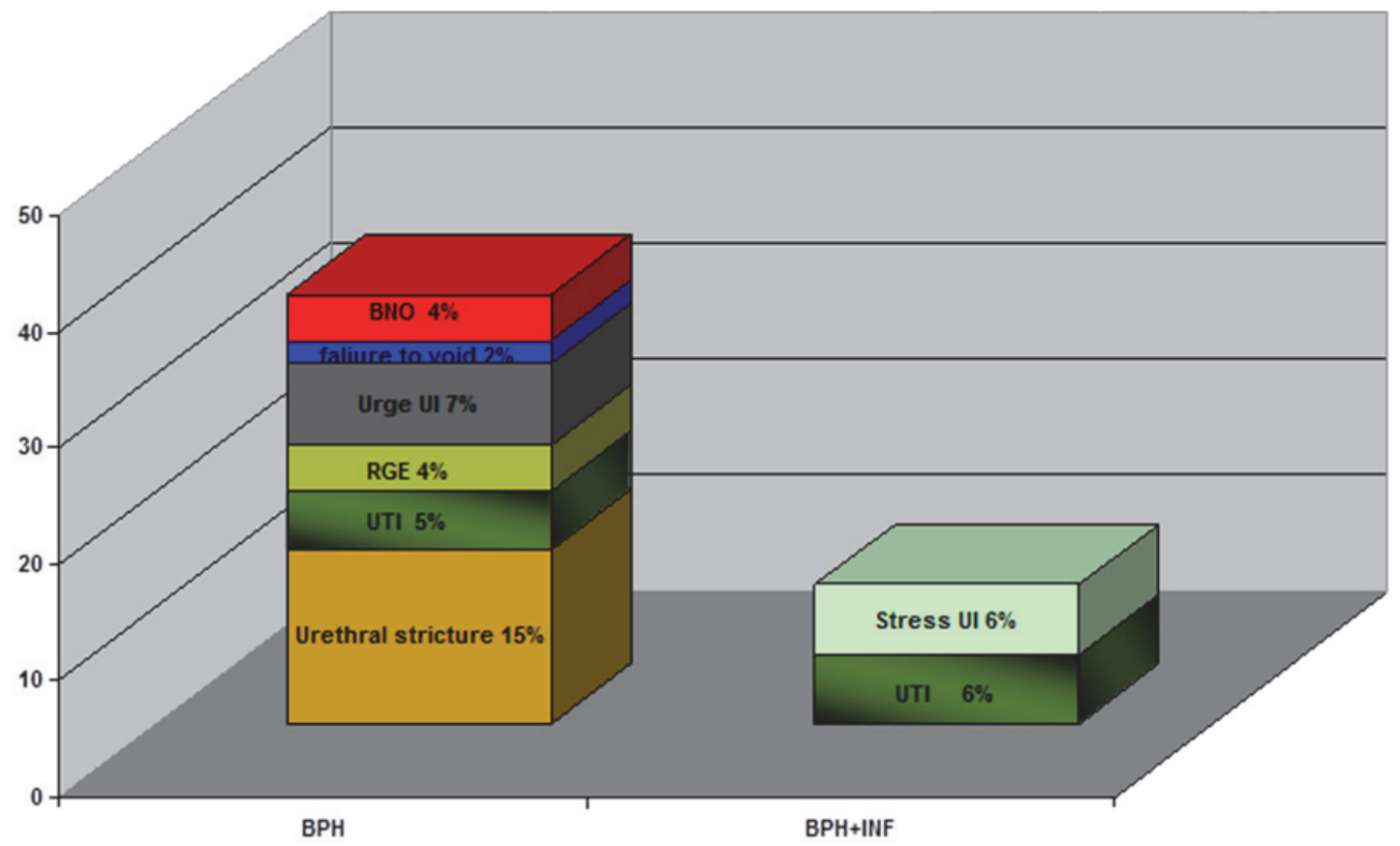

Figure 3. Type of complications in both histopathology divided groups. (BNO: Bladder neck obstruction; Urge UI: Urge urine incontinence; RGE: Retrograde ejaculation; UTI: Urinary tract infection; Stress UI: Stress urine incontinence).

the incidence of AUR reaches as high as $57 \%$ i.e., almost double the international reports of $30 \%{ }^{[1]}$, in our institute AUR is as high as $54 \%$.

Few papers address the role of prostate inflammation in BPH progression, risk AUR and response to medical therapy ${ }^{[9-12]}$. Chughtai et al. ${ }^{[13]}$ postulated inflammation as the third component in $\mathrm{BPH}$ pathogenesis and symptom progression by activating CD4+ lymphocytes. In this study, our hypothesis was that AUR has an effect on the patient postoperative outcome (complication and satisfaction), but the results showed that in both comparable groups (retention and elective groups) there was no difference in the postoperative outcome between them. Secondary analysis of prostate size and patient age, showed no effect on both postoperative satisfaction and complication rates.

The presence of inflammatory cells in the BPH histopathology showed a significant effect on patient satisfaction. We believe that it has unexplainable protective effect on postoperative complication rate but the $p$ value was not significant because of the absence of histopathology in BNI cases (Fig. 3).

\section{Conclusion}

Retention rate in our study is comparable to international reports. History of urinary retention does not have any effect on postoperative satisfaction nor complication rate, while the presence of inflammatory cells in the BPH histopathology showed a positive effect on patients' post-operative satisfaction and a protective effect on prostatic post-operative complications.

\section{Acknowledgement}

We would like to thank Professor Hisham Mosli for his efforts in reviewing the manuscript.

\section{Conflict of Interest}

The author has no conflict of interest.

\section{Disclosure}

The author did not receive any type of commercial support either in forms of compensation or financial for this study. The author has no financial interest in any of the products or devices, or drugs mentioned in this article. 


\section{Ethical Approval}

\section{Obtained}

\section{References}

[1] Mosli HA, Atwa MA, Mahassini SH. Benign prostatic hyperplasia. The Saudi perspective in the year 2000. Saudi Med J 2000; 21(10): 915-920.

[2] Chapple CR. BPH disease management, introduction and concluding remarks. Eur Urol 1999; 36 (Suppl 3): 1-6.

[3] Fitzpatrick JM, Artibani W. Therapeutic strategies for managing BPH progression. Eur Urol Suppl 2006; 5(20): 997-1003.

[4] Montirioni R, Valli M, Fabris G, Treatment of benign prostatic hyperplasia with 5-alpha-reductase inhibitor: morphological changes in patients who fail to respond. J Clin Pathol 1996; 49(4): 324-328.

[5] Calais Da Silva F, Marquis P, Deschaseaux P, Gineste $J L$, Cauquil J, Patrick DL. Relative importance of sexuality and quality of life in patients with prostatic symptoms. Eur Urol 1997; 31(3): 272-280.

[6] Emberton M, Martoana G. BPH: social impact and patient's perspective. Eur Urol Suppl 2006; Suppl 5: 991-996.

[7] Hong SJ, Rayford W, Valiquette L, Emberton M. The importance of patient perception in the clinical assessment of benign prostatic hyperplasia and its management. BJU Int 2005; 95(10: 15-19.

[8] Emberton M, Zinner N, Michel MC, Gittelman M, Chung MK, Madersbacher S. Managing the progression of lower urinary tract symptoms/benign prostatic hyperplasia: therapeutic options for the man at risk. BJU Int 2007; 100(2): 249-253.

[9] Briganti A, Capitanio U, Suardi N, Gallina A, Salonia A, Bianshi M, Tutolo M, Di Girolamo V, Guazzoni G, Rigatti P, Montorsi F. Benign prostatic hyperplasia and its aetiologies. Eur Urol Suppl 2009; Suppl 8: 865-871.

[10] De Nunzio C, Aronson W, Freedland SJ, Giovannucci E, Parsons JK. The correlation between metabolic syndrome and prostatic diseases. Eur Urol 2012; 61(3): 560-570.

[11] De Nunzio C1, Kramer G, Marberger M, Montironi R, Nelson W, Schröder F, Sciarra A, Tubaro A. The controversial relationship between benign prostatic hyperplasia and prostate cancer: the role of inflammation. Eur Urol 2011; 60(1): 106-117.

[12] Steiner G, Gessl A, Kramer G, Schöllhammer A, Förster $\mathrm{O}$, Marberger M. Phenotype and function of peripheral and prostatic lymphocytes in patients with benign prostatic hyperplasia. J Urol 1994; 151(2): 480-484.

[13] Chughtai B, Lee R, Te A, Kaplan S. Role of inflammation in benign prostatic hyperplasia. Rev Urol 2011; 13(3): 147150. 


\section{تاثير احتباس البول على نتائج عمليات البروستات ورضى المرضى والمضاعفات بعد العمليه}

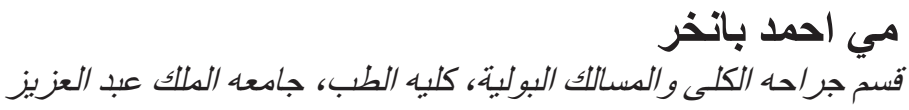

$$
\begin{aligned}
& \text { جلة ـ المملكة العربية السعودية العيلية }
\end{aligned}
$$

المستخلص. ـ بهدف البحث الى دراسة تأثير احتباس البول على رضى المرضي بعد عمليات البروستات ومضاعفات

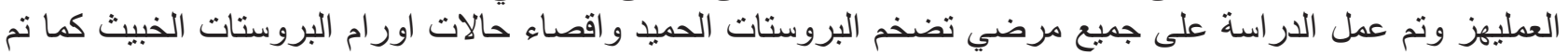

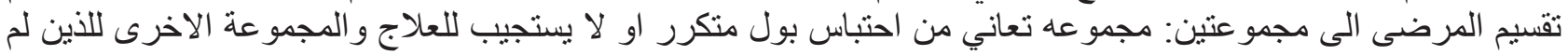

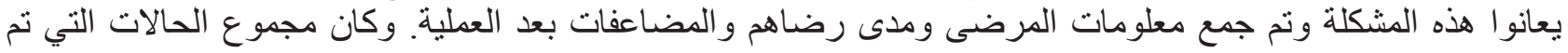

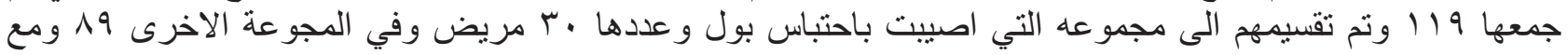

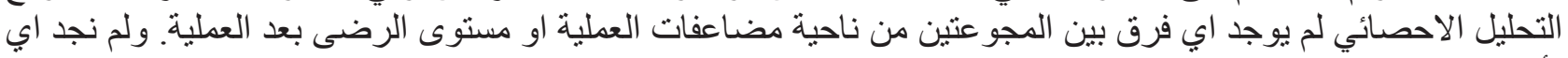

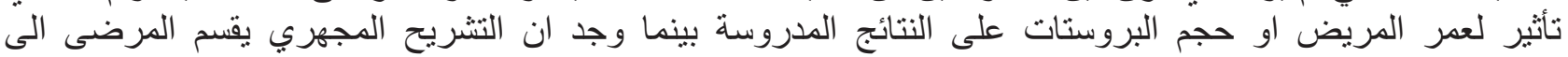

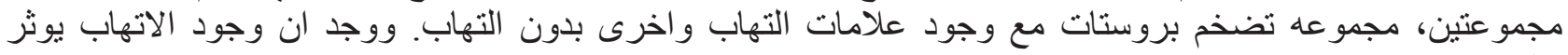

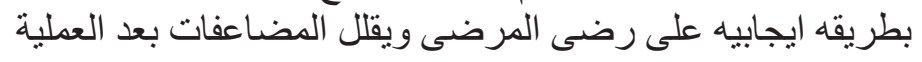

